action. The evidence of deign may be irresistible in cases where we cannot indicate its limits. We can only infer with greater or less probability, according to circumstances, and especially according to relation to ends. Better evidence than that of exquisite adaptation of means to ends is seldom, if ever, obtainable of human intention, and in the nature of the case it is the only kind of evidence which is scientifically available in regard to superhuman intention. Now if means and ends are predicable of inorganic nature at all, it is only by remote and indirect implication; while in organic nature the inference is direct and unavoidable. With what propriety, then, can it be affirmed that organic nature furnishes no other and no better evidence of underlying intelligence than inorganic nature? The evidence is certainly other, and to our thinking better.

To make the contrary supposition tenable, it must be shown that natural selection scientifically accounts for the adaptation ; that the survival of only the very best adapted, out of the brood of more or less adapted to the environment at the time, gives sufficient scientific explanation of the adaptability or actual adaptation of the organism. Certainly this has not yet been done, and it seems incredible that it ever will be. That organisms have undergone changes as the Darwinian theory piedicates, and that these changes have been picked out and led on by natural selection, seems to me most probable. That the action of the environment in some wholly unexplained way induces organisms to movement and change which would not otherwise occur, is also probable; but such change appears to be a respoase of the organisms to the physical surroundings and stimuli. And this most important factor in the result receives no explanation from the natural selection which operates upon it or co-operates with it. In other words, real causes have been assigned under which, given the requisite changes, the actual diversity and adaptations of plants and animals must or may have come to pass. But none have been assigned under which the organisms must have responded in the ways they do, or have responded at all, to the influences of the environment. Yet this is the very gist of the matter. The whole tenor of Darwin's writings and many explicit statements assure us that he completely recognised this distinction, which less exact minds overlook. If this distinction is valid, then the conclusion is at least premature which affirms "thət the arsument from teleology has been dislodved by the theory of natural selection," and its special value, as derived from adaptations in organic nature, utterly and for ever destroyed."

Cambridge, U.S.

\section{Intelligence in Animals}

Mr. ROMAnes remarks in his book that there are few recorded instances of intelligence in bears; the following facts may therefore be worth recording :- In the Clifton Zoological Gardens there are two female Polar bears between two and a half and three years old, which came here quite young. One of these shows remarkable intelligence in cracking cocoa-nuts. A nut was thrown to-day into the tank; it sank a long way, and the bear waited quietly till after some time it rose a little ont of her reach. She then made a current in the water with her paw, and thus brought it within reach. This babit has already been several times noticed in Polar bears. She then took it on shore, and tried to break it by leaning her weight on it with one paw. Failing in this, she took the nut between her fore-paws, raised herself on her hind-legs to her full height, and tirew the nut forwards against the bars of the den, three or four feet off. She then again leant her weight on it, hoping she bad cracked it; but failed again. She then repeated the process, this time successfully. The keeper told me she employed the same method to break the leg-bone of a horse. That this is the result of individual experience, and not of instinct, is clear from the fact that her companion has not learnt the trick of opening them thus, nor conld this one do it when she first came. The method of throwing is precisely similar to that adopted by the Cebus monkey described by Mr. Romanes.

Clifton College, Clifton, Bristol, January I5

On a Relation existing between the Latent Heats, Specific Heats, and Relative Volumes of Volatile Bodies

As I do not find that the following relation between the latent heat of evaporation, the expansion undergone in changing into the gaseous state, and the specific heat of a volatile body has been previously pointed out ; and as, if verified, it might be of some value in the determination of one or other of the above quantities I submit it, not however without considerable diffdence, to the readers of NATURE.

Briefly stated the relation stands thus-

The latent heat of gasification at constant pressure of any body, divided by the product of the relative volume of the gas and the specific heat of the body is approximately constant; or, if

$\lambda=$ latent heat of gasification of any body,

$v=$ relative volume of the gas; i.e. the vol. of the body on assuming the gaseous state compared with its vol. as a liquid,

$s=$ specific heat of the body. Then

$$
\frac{\lambda}{v \times s}=\text { const. }
$$

The calculated value of this constant approximates to 0.8 , as will be seen in the following table.

The letters $\lambda, v$, and $s$, heading columns 2,3 , and 4 , have the same signification as above.

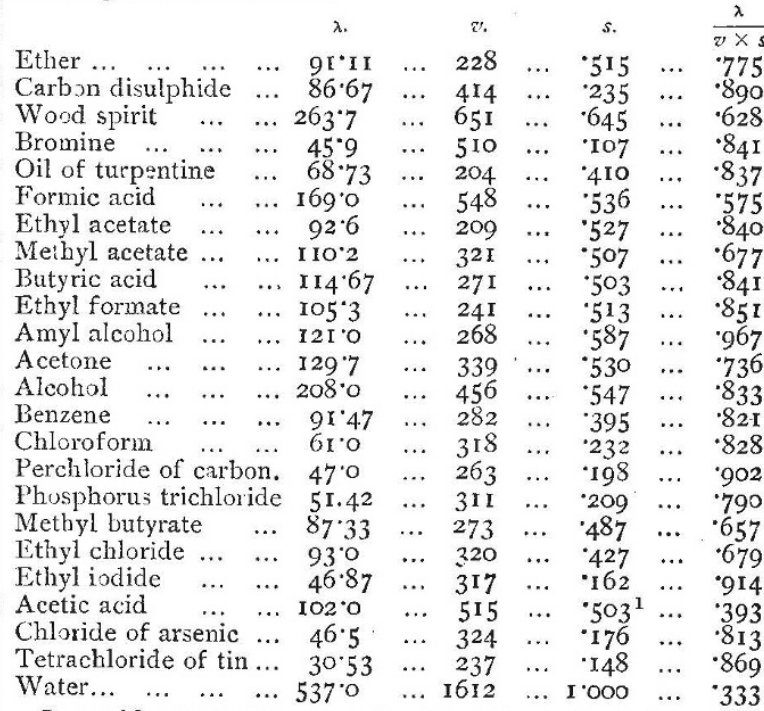

It would appear then that the latent heat of a body may be considered as approximately proportional to the expansion of the body in vaporising and to its specific heat; and that the amount of heat required to convert a unit mass of the body at the boiling point from the liquid to the gaseous state, is equal to an amount of heat which would raise through one degree a quantity of the body in the liquid state which is approximately proportional to the expansion undergone by the liquid on evaporating.

It will be noticed that among the bodies instanced in the table there are some which appear to be very far indeed from accord. ing with the relationship in question. Notably acetic acid and water; of these, however, water presents so many peculiarities that perhaps it may be allowable to consider this as only adding one more to their number. In the case of acetic acid it is noteworthy that in plotting the curve of the latent heats of the group of acids of which acetic acid is a member, Favre and Silbermann found an irregularity arising from this body. It is, at any rate, possible that this irregularity may mean an error in the determination of the latent heat of this body.

Considering the difficulties which attend the accurate determination of Jatent heats, relative volumes, and specific heats of the several bodies, and that, of course, an error in any one of these will introduce inaccuracies into the constant, it may well be supposed that some, at least, of the variations noticeable in the results tabulated arise from inaccurate data. Further, there are in many cases two or more distinct determinations of these physical properties extant, of which one might be so selected in each case as to reduce the variations occurring in the constant to a minimum.

Trinity College, Dublin

F. TROUTON

\section{The Gresham Funds}

IN an account of a meeting of the Common Council of the City of London, held last week, I read in the Times that the 1 Varies with temperature of determination irregularly. 